\title{
Análise de uma habitação multifamiliar sobre os aspectos de conforto ambiental e ergonomia no município de Teófilo Otoni/MG
}

\author{
Analysis of a multifamily dwelling on aspects of environmental \\ comfort and ergonomics in the municipality of Teófilo Otoni / MG
}

IARA FERREIRA DE REZENDE COSTA

Mestre em Engenharia Civil, UFVJM, iara.ferreira@ufvjm.edu.br

THAÍS MAYARA RODRIGUES GOMES Aluna de Graduação em Engenharia Civil, UFVJM, tmthaismayara@hotmail.com

MILENA CELESTINO DE OLIVEIRA Aluna de Graduação em Engenharia Civil, UFVJM, milla_1206@hotmail.com

LAVÍNIA FERNANDES LIMA

Aluna de Graduação em Engenharia Civil, UFVJM, lala_limaf@hotmail.com

ALCINO DE OLIVEIRA COSTA NETO

Mestre em Engenharia Civil, UFVJM, alcino.neto@ufvjm.edu.br

\section{RESUMO}

A análise das condições ergonômicas de residências abrange desde a orientação dos cômodos, layout dos móveis no espaço, fluxos de circulação, privacidade, usabilidade, o que inclui também o conforto ambiental. Fatores como luz, temperatura, acústica, ventilação e iluminação natural quando bem resolvidos, são de grande relevância para a contribuição do bem-estar dos moradores, pois criam um ambiente agradável e funcional. Diante do cenário precedente, este trabalho apresenta uma análise de conforto ambiental e de condições ergonômicas para uma habitação multifamiliar localizada no município de Teófilo Otoni/MG, cidade caracterizada por condições climáticas adversas. Os procedimentos metodológicos envolvem a verificação das dimensões mínimas dos mobiliários, assim como a circulação entre os mesmos e possíveis anteparos, análise da disposição e orientação dos cômodos, do mesmo modo que as suas dimensões mínimas, caracterizada pela área total, pé-direito, bem como a área das aberturas em relação à área do piso. Os resultados mostraram que a habitação possui deficiências, com uma preocupação mínima com a circulação e as condições de ergonomia, uma necessidade de redimensionamento espacial e a melhoria no posicionamento das aberturas. Vale salientar que os critérios observados interferem diretamente na qualidade de vida, conforto e saúde dos usuários da habitação.

PALAVRAS-CHAVE: Conforto ambiental; ergonomia; habitação; Teófilo Otoni 


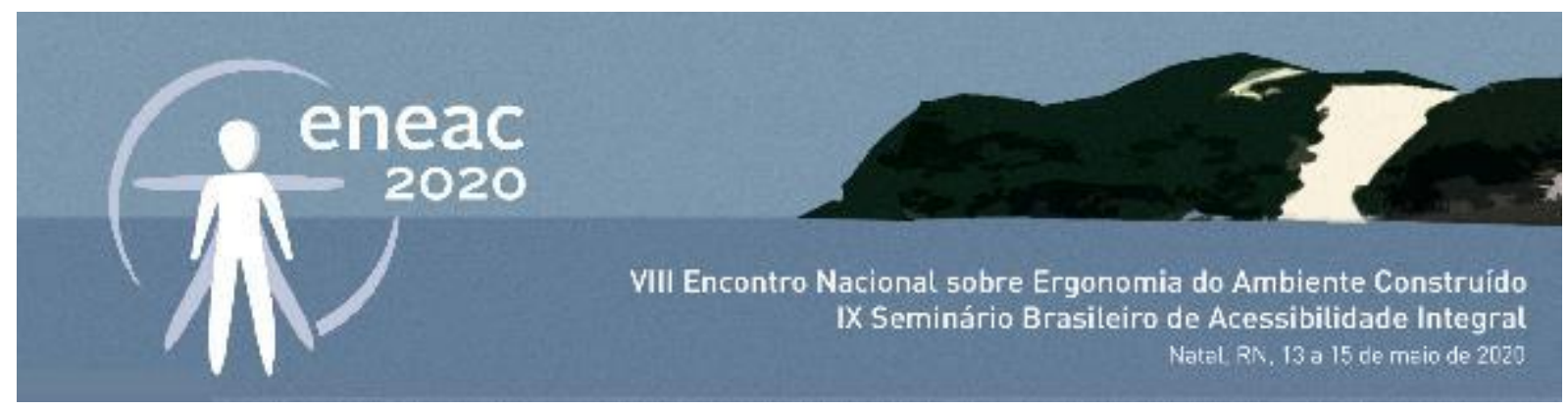

\section{ABSTRACT}

The analysis of the ergonomic conditions of residences covers from an orientation of the rooms, layout of furniture in the space, circulation flows, privacy, usability, and also includes environmental comfort. Factors such as light, temperature, acoustics, ventilation and natural lighting when properly resolved, are of great importance to contribute to the well-being of residents, as they create a pleasant and functional environment. In view of the preceding scenario, this work presents an analysis of environmental comfort and ergonomic conditions for a multifamily housing located in the municipality of Teófilo Otoni /MG, a city characterized by adverse conditions. The methodological procedures involve the selection of the minimum dimensions of the furniture, such as circulation between them and possible bulkheads, the analysis of the layout and the orientation of the models, in the same way as their minimum dimensions, characterized by the total area, right foot, as well as as an area of the openings in relation to the floor. The results that the housing has deficiencies, with a minimum concern with circulation and ergonomic conditions, a need for spatial resizing and an improvement in the positioning of the openings. It is worth noting that the candidates observed directly interfere in the quality of life, comfort and health of the users of the housing.

KEYWORDS: Environmental comfort; ergonomics; housing; Teófilo Otoni

\section{INTRODUÇÃO}

Na esfera do ambiente construído, o homem permanece com a pesquisa pelas características mais adequadas ao espaço interno. Considerando a necessidade de qualidade de vida na habitação, novas propostas e soluções são discutidas por profissionais das áreas mais diversificadas. Assim, surge a análise ergonômica nas habitações propondo um aprofundamento entre a tarefa, o ambiente físico, e a relação entre o usuário e o meio.

Para as autoras Mont'Alvão e Villarouco (2011) não é possível abordar uma arquitetura preocupada com seus usuários sem a compreensão das suas aspirações e anseios ambientais. Assim, as referidas autoras citam a ergonomia e sua relação com os ambientes construídos, ao ressaltar conceitos como a percepção ambiental, antropometria, ergonomia cognitiva, além do conforto ambiental de uma forma geral.

O interesse por essa racionalização da habitação ocorreu a partir do século XX fundamentado principalmente nos conceitos elaborados por Le Corbusier, um dos ícones do movimento moderno, conforme Souza (2013). Suas ideias tiveram boa repercussão, em especial, pelo advento do pósguerra na Europa, onde era necessário encontrar soluções para a crise do déficit habitacional. Com as considerações de Le Corbusier, pela primeira vez começou a se pensar na relevância da funcionalidade e na preocupação com a valorização dos equipamentos e mobiliário internos das habitações, associando funcionalidade e conforto.

Segundo Lamberts et al. (2005) o conforto térmico é definido como estado mental relacionado à satisfação do ser humano no ambiente térmico em que está inserido. Quando não alcançada esta satisfação, o homem apresenta a sensação de frio ou calor. Conforme Labaki e Bueno-Bartholomei (2001), apesar de ser um tema largamente pesquisado por todo o mundo, há grande ocorrência de ambientes inadequados, gerando custos sociais e gastos com usos de equipamentos condicionadores 


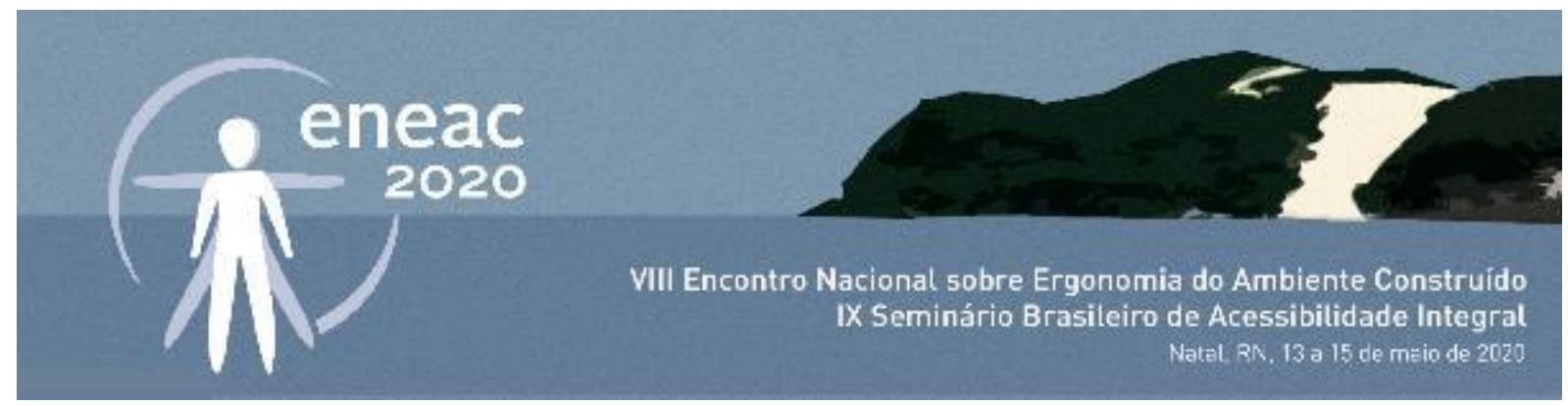

térmicos.

Porém em um cenário nacional, a tipologia das habitações ratifica a monotonia e a despreocupação em questões de conforto ambiental e ergonomia. Os quesitos mais prejudicados são a iluminação e a ventilação, uma vez que as aberturas de janelas e portas apresentam a mesma conformação, independente da orientação solar.

Trabalhos como Lopes (2006), Vasconcelos (2011), Paiva e Santos (2012), Lelis et al.(2013), Lelis (2015) e Crespilho et al. (2016) abordam a análise ergonômica das habitações, focalizando em aspectos como acessibilidade, habitabilidade e conforto ambiental, com a geração de dados que auxiliam na compreensão das deficiências ou qualidades dos projetos atuais, alicerçado em estudos de caso nas mais diversas localizações no Brasil e em Portugal.

Dentro da análise ergonômica projetual, o presente trabalho realizado em uma habitação multifamiliar no município de Teófilo Otoni/MG, propõe definir em cada ambiente avaliado as medidas consideradas minimamente confortáveis, com base na pesquisa bibliográfica, que se fundamentará, majoritariamente, no Código de Obras do município. Assim como a disposição e orientação dos mesmos em relação ao movimento aparente do sol. Ainda o trabalho conta com o estudo da verificação das dimensões mínimas dos mobiliários e a circulação entre os mesmos, estabelecendo relações a respeito da ergonomia associadas a algumas variáveis de conforto ambiental e à qualidade dos projetos habitacionais.

\section{METODOLOGIA}

Este trabalho relata um estudo desenvolvido para analisar as características específicas de uma habitação no município de Teófilo Otoni, no estado de Minas Gerais, enquanto qualidade projetual e a capacidade de proporcionar bem-estar e conforto aos moradores. Na cidade em evidência há inúmeras habitações construídas em diferentes épocas, e não muito diferente do cenário nacional, com padrões de construção bem distintos. A princípio, espera-se que as moradias atendam aos requisitos mínimos de habitabilidade, dispostos no Código de Obras do município, assim como nas normas técnicas nacionais.

O município em questão, segundo dados do Instituto Brasileiro de Geografia e Estatística (IBGE, 2018), está localizado mais precisamente no Vale do Mucuri (região nordeste do estado), com latitude $17^{\circ} 51^{\prime} 32^{\prime \prime}$ Sul e longitude $41^{\circ} 30^{\prime} 32^{\prime \prime}$ Oeste a 347 metros de altitude. O clima da cidade é caracterizado como tropical quente semiúmido ou tropical com estação seca.

\section{Dimensões mínimas para o mobiliário da habitação}

Para cada cômodo de uma residência o mobiliário possui medidas apropriadas, as quais são definidas considerando a função de cada móvel e a produtividade do ser humano. Portanto, para a análise e avaliação de mobiliário foram utilizadas as dimensões de móveis estabelecidas pelos autores Pronk (2003) e Pedro et al. (2006).

A Tabela 1 evidencia as dimensões ideais de comprimento, largura e altura para cada um dos móveis da residência analisada. Ressalta-se que foram utilizados os móveis mais comuns em uma moradia. 


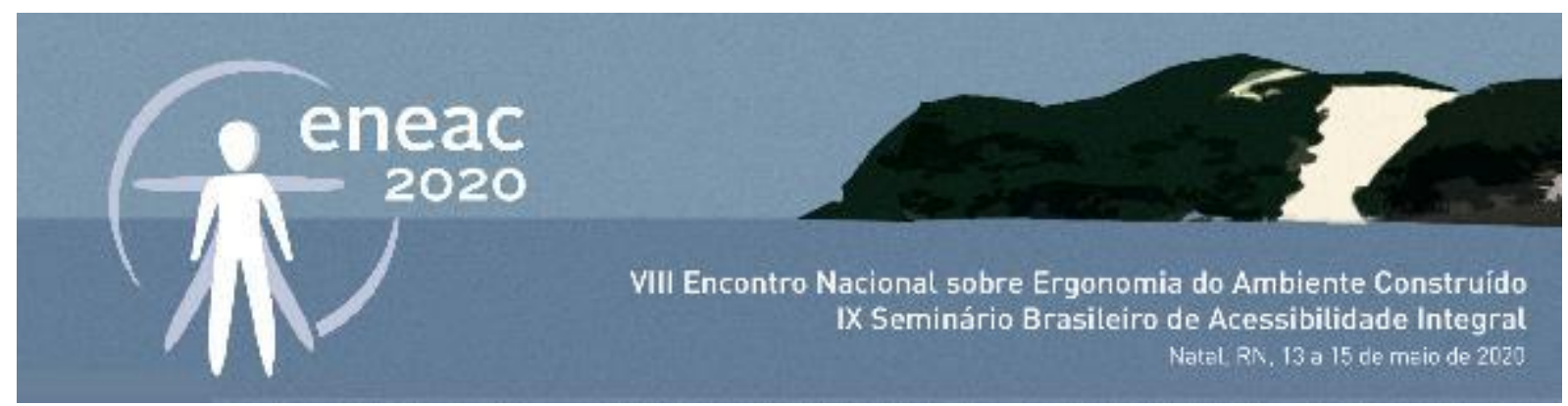

Tabela 1: Dimensões mínimas do mobiliário

\begin{tabular}{c|c|c|c} 
Móvel & Comprimento $(\mathrm{cm})$ & Largura $(\mathrm{cm})$ & Altura $(\mathrm{cm})$ \\
\hline Cama de casal & 190 & 130 & - \\
\hline Cama individual & 190 & 80 & - \\
\hline Roupeiro individual & 80 & 60 & 155 \\
\hline Cômoda simples & 80 & 40 & - \\
\hline Mesa de trabalho & 110 & 50 & - \\
\hline Mesa (4 lugares, retangular) & 130 & 75 & 210 \\
\hline Mesa (4 lugares, quadrada) & 90 & 90 & - \\
\hline Armário & 70 & 60 & - \\
\hline Fogão (4 bocas) & 60 & 60 & 90 \\
\hline Geladeira & 52 & - & 80 \\
\hline Cuba & 45 & 50 & 81 \\
\hline Tanque de lavar roupas & 56 & 42 & 50 \\
\hline
\end{tabular}

Fonte: Adaptado de Pronk (2003) e Pedro et al. (2006).

Ainda foram utilizadas as mesmas referências mencionadas anteriormente para a determinação das dimensões para circulação e possíveis trabalhos em frente às mobílias de maior uso para realização de tarefas domésticas, e para estabelecer a distância mínima exigida entre mobílias que são expressas na Tabela 2 e na Tabela 3, respectivamente.

Tabela 2: Circulação e trabalho

\begin{tabular}{c|c} 
Circulação e trabalho em frente à/ao & Medida $(\mathrm{cm})$ \\
\hline Fogão & 120 \\
\hline Lavatório & 70 \\
\hline Tanque de lavar roupas & 100
\end{tabular}

Fonte: Adaptado de Pronk (2003) e Pedro et al. (2006).

Tabela 3: Distância mínima entre mobílias

\begin{tabular}{c|c} 
Distância entre & Medida $(\mathrm{cm})$ \\
\hline Cama e roupeiro & 95 \\
\hline Mesa e parede & 75 \\
\hline Tanque e prateleira superior (Lavanderia) & 95 \\
\hline \multicolumn{2}{c}{ Fonte: Adaptado de Pronk (2003) e Pedro et al. (2006). }
\end{tabular}

Como critério para avaliação, empregou-se o termo "Atende" para quando as medidas estavam em consonância com os valores apresentados nas tabelas anteriores e "Não atende" para quando não estavam.

\section{Dimensões mínimas para as dependências da residência}

O Código de Obras do município de Teófilo Otoni (2016) delibera sobre as normas e especificações que devem ser adotadas para a execução das edificações, de modo que haja um mínimo de conforto e bem-estar para os usuários, atendendo às necessidades de habitabilidade, espacialidade, e organização das dependências deste ambiente construído. Portanto, a presente referência auxiliou como base técnica para a definição da área mínima, do valor mínimo para o pé-direito, bem como a 


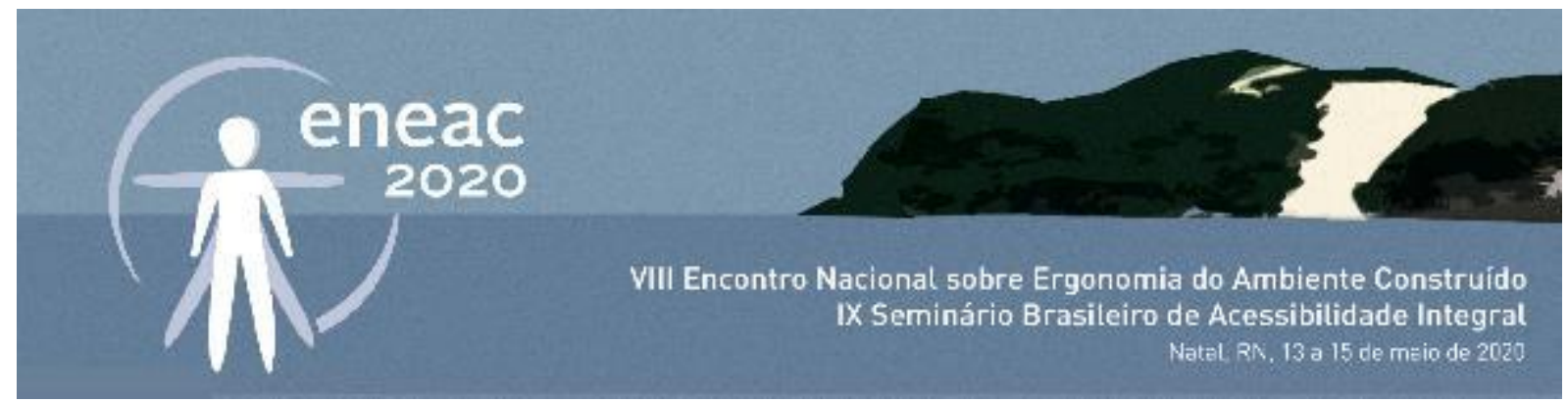

área das aberturas em relação à área do piso, fator este relacionado à ventilação e a iluminação. As medidas estão expressas na Tabela 4.

\begin{tabular}{|c|c|c|c|}
\hline Compartimento & Área $\left(\mathrm{m}^{2}\right)$ & Áreas das aberturas em relação à área do piso (\%) & Pé-direito $(\mathrm{m})$ \\
\hline Sala de estar & 8,0 & 16,7 & 2,5 \\
\hline Dormitórios & 8,0 & 16,7 & 2,5 \\
\hline Cozinha & 4,0 & 16,7 & 2,5 \\
\hline Copa & 6,0 & 16,7 & 2,5 \\
\hline Banheiro & 2,0 & 12,5 & 2,2 \\
\hline Lavanderia & 4,0 & 12,5 & 2,2 \\
\hline
\end{tabular}

Fundamentada a partir das medidas listadas anteriormente, foi realizada a avaliação da habitação, empregando o termo "Atende" para os parâmetros que estão em conformidade com o Código de Obras e "Não atende" para os que estão em desacordo.

\section{Disposição das dependências em relação à orientação solar}

Como metodologia de avaliação em relação à orientação solar de cada dependência da residência, foram estabelecidos parâmetros baseados na análise da carta solar do município de Teófilo Otoni.

A partir do uso do software Analysis SOL-AR 6.2 e da latitute local $(-17,86$ ) foi possível traçar a carta solar da cidade, conforme Figura 1.

Figura 1: Carta solar de Teófilo Otoni

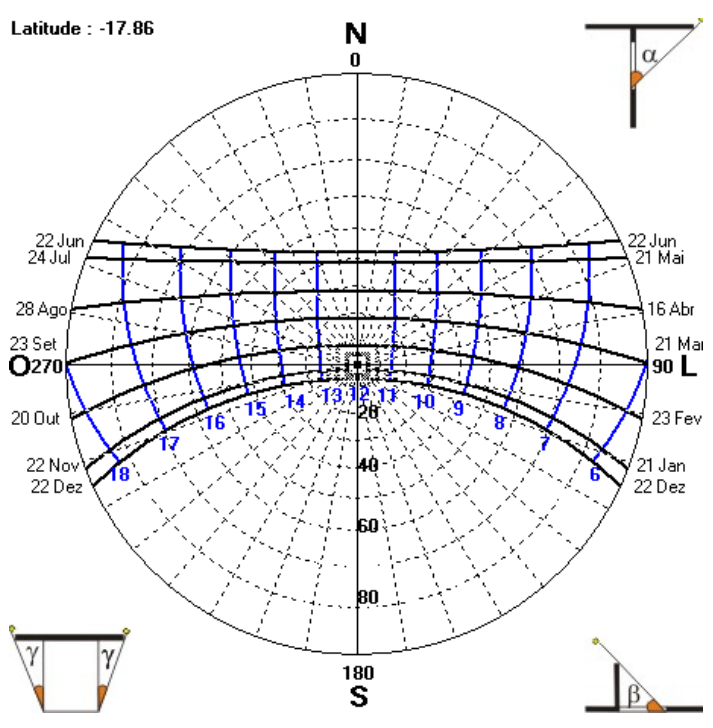

Fonte: Analysis SOL-AR 6.2, 2020.

Como critério de classificação foi analisada a direção para a qual está voltada a abertura do cômodo, 


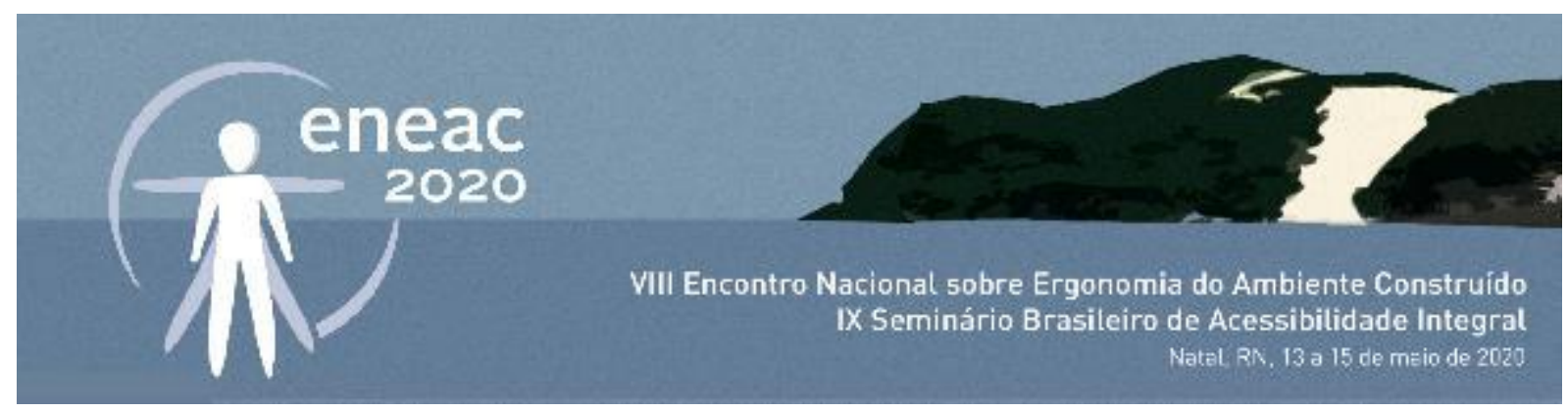

ponderando a orientação como Ótima (O), Boa (B) e Ruim (R).

Analisando as dependências como o banheiro, a cozinha e a lavanderia, percebe-se que regiões consideradas dentro de uma habitação multifamiliar como áreas molhadas, além de serem cômodos de permanência transitória dos moradores. Por consequência, indica-se que sejam voltados para direções com incidência solar durante todo o ano, no período vespertino em especial, pois possui maior radiação global incidente (Ig), o que favorece a secagem e manutenção destes ambientes. Para os presentes cômodos ponderou-se (O) a orientação Oeste, (B) as direções Norte e Sul e (R) a direção Leste.

A copa é considerada de forma geral, uma localidade de permanência transitória, no qual os usuários passam apenas uma discreta parte de seu tempo. À vista disso, sua abertura pode ser orientada para direções que recebam incidência solar durante o dia, sem afetar o bem-estar dos usuários na residência, já que em muitas vezes parte da premissa que é um ambiente utilizado com mais intensidade no período noturno. Por conseguinte, considerou-se (O) a orientação Norte, (B) a orientação Leste e (R) as orientações Oeste e Sul.

Por serem locais de permanência prolongada dos indivíduos, é ideal que a sala e os dormitórios estejam voltados para uma direção que usufrui de incidência solar durante todo o ano, porém apenas no período da manhã, o qual apresenta os valores mais baixos de radiação global incidente, de modo que proporcione um ambiente termicamente favorável e auxilie no controle da proliferação de fungos e ácaros. Destarte, considerou-se (O) para os referidos compartimentos a direção Leste, (B) a direção Norte e (R) as direções Sul e Oeste.

A Tabela 5 expõe a classificação resumo quanto à orientação solar apropriada para cada dependência, conforme o texto precedente.

Tabela 5: Orientação solar adequada por dependência

\begin{tabular}{c|c|c|c|c|c|c} 
Classificação & Sala de estar & Dormitórios & Cozinha & Copa & Banheiro & Lavanderia \\
\hline O & Leste & Leste & Oeste & Norte & Oeste & Oeste \\
\hline B & Norte & Norte & Norte/Sul & Leste & Norte/Sul & Norte/Sul \\
\hline R & Oeste/Sul & Oeste/Sul & Leste & Oeste/Sul & Leste & Leste \\
\hline \multicolumn{7}{c}{ Fonte: elaborado pelos autores, 2020. }
\end{tabular}

Ressalta-se que a orientação evidenciada na Tabela 5 corresponde à direção para a qual está voltada a abertura do cômodo.

\section{RESULTADOS}

Partindo da metodologia apresentada anteriormente, foram feitas análises ponderando sobre os aspectos de ambiente habitável, conforto térmico e mobiliário da residência.

O apartamento escolhido para a análise localiza-se no centro da cidade, na Rua Epaminondas Otoni. A Figura 2 evidencia o croqui da moradia. 

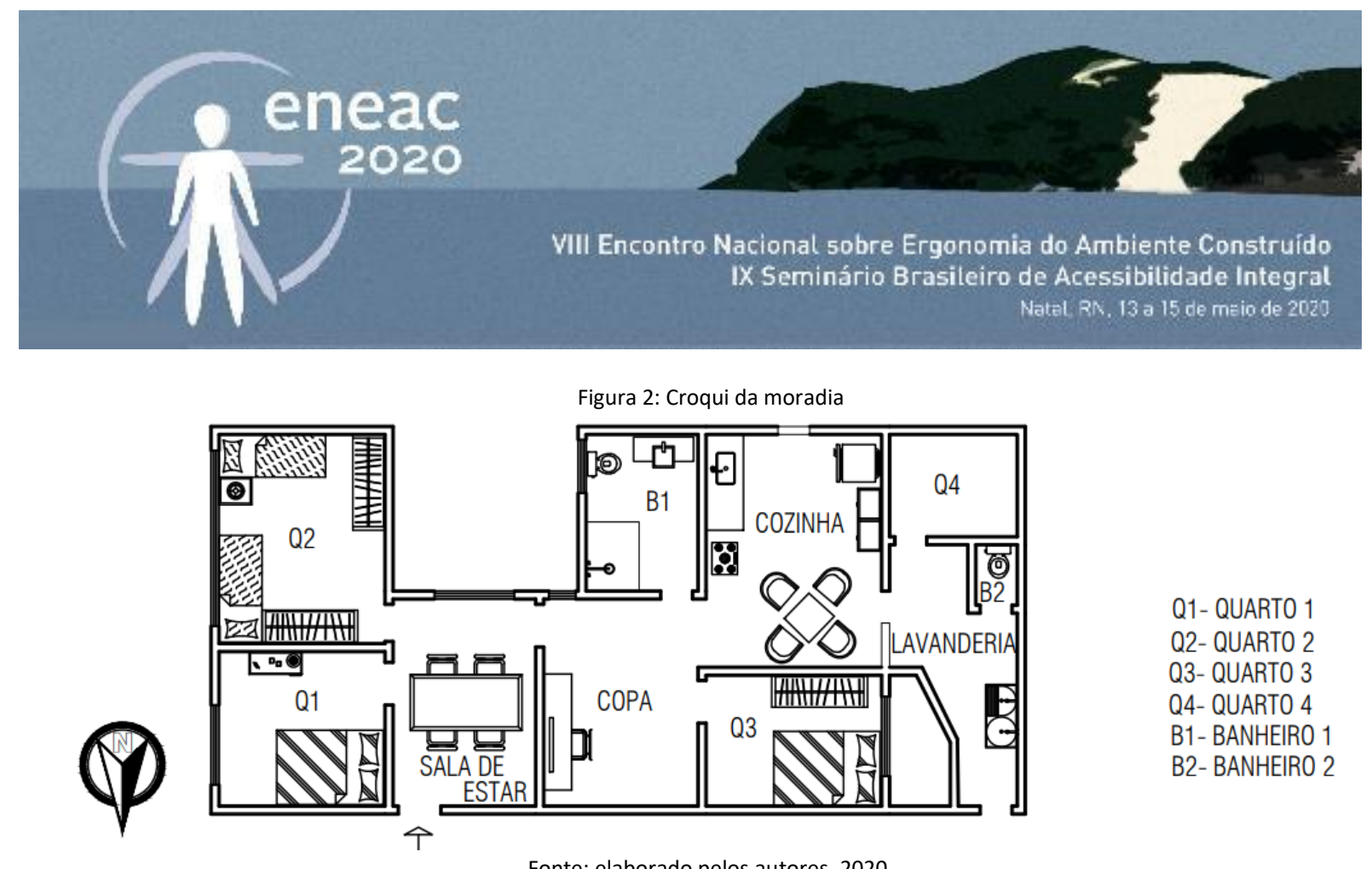

Fonte: elaborado pelos autores, 2020.

\section{Mobiliário}

A Tabela 6 dispõe as avaliações quanto às dimensões do mobiliário para a moradia.

\begin{tabular}{c|c|c|c|c}
\multicolumn{7}{c}{ Tabela 6: Medidas e avaliação do mobiliário } \\
Móvel & Comprimento $(\mathrm{cm})$ & Largura $(\mathrm{cm})$ & Altura $(\mathrm{cm})$ & Avaliação \\
\hline Cama de casal (Q1) & 185 & 135 & - & Não atende \\
\hline Cama de casal (Q3) & 188 & 139 & & Não atende \\
\hline Cama individual (Q2) & 204 & 95 & - & Atende \\
\hline Cama individual (Q2) & 205 & 100 & & Atende \\
\hline Cômoda simples (Q1) & 117 & 44 & - & Atende \\
\hline Roupeiro individual (Q2) & 180 & 46 & 192 & Não atende \\
\hline Roupeiro individual (Q2) & 165 & 42 & 184 & Não atende \\
\hline Roupeiro individual (Q3) & 155 & 40 & 185 & Não atende \\
\hline Mesa de trabalho & 119 & 60 & - & Atende \\
\hline Mesa (4 lugares, quadrada) & 70 & 70 & - & Não atende \\
\hline Mesa (4 lugares, retangular) & 120 & 75 & - & Não Atende \\
\hline Armário (Cozinha) & 106 & 25 & 157 & Não atende \\
\hline Fogão (4 bocas) & 50 & 50 & - & Não atende \\
\hline Geladeira & 62 & - & - & Atende \\
\hline Cuba & 106 & 25 & 157 & Não atende \\
\hline Tanque de lavar roupas & 100 & 49 & 90 & Atende \\
\hline Bancada com lavatório (B1) & - & 34 & 85 & Não atende \\
\hline
\end{tabular}

Fonte: elaborado pelos autores, 2020.

Nota-se que aproximadamente $65 \%$ das mobílias não atendem às medidas mínimas estabelecidas nas referências utilizadas para a presente análise. Vale salientar que o Q4 não apresenta mobílias e que o B2 não possui bancada com lavatório.

As tabelas 7 e 8 contém, respectivamente, a avaliação quanto às medidas de circulação e trabalho em frente às mobílias, e a distância necessária entre elas. 


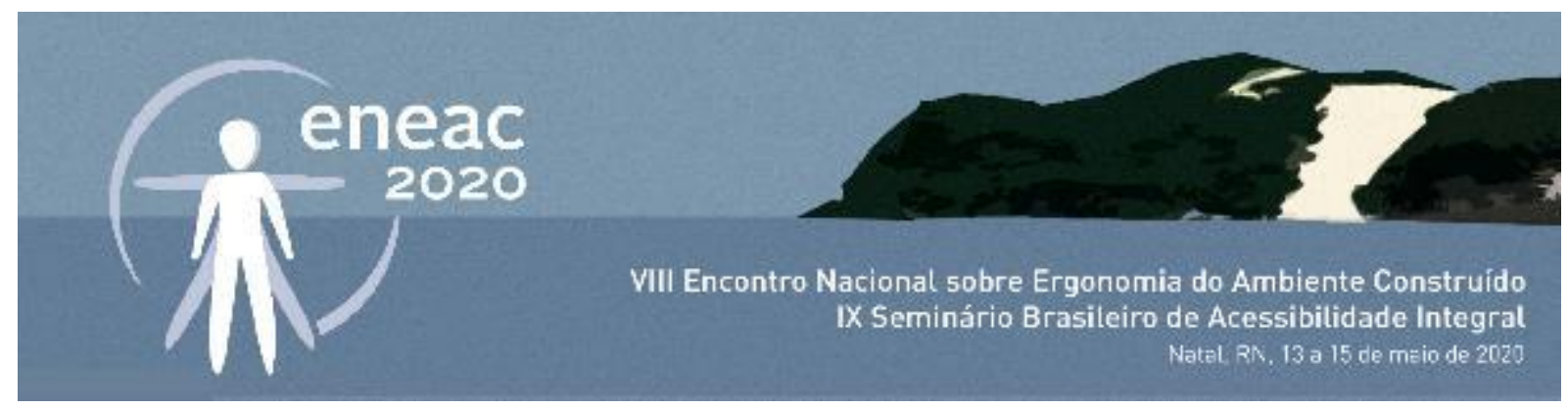

Tabela 7: Medidas e avaliação da circulação e trabalho

\begin{tabular}{c|c|c} 
Circulação e trabalho em frente à/ao & Medida $(\mathrm{cm})$ & Avaliação \\
\hline Fogão & 148 & Atende \\
\hline Lavatório (B1) & 90 & Atende \\
\hline Tanque de lavar roupas & 54 & Não atende \\
\hline
\end{tabular}

Fonte: elaborado pelos autores, 2020.

Tabela 8: Medidas e avaliação da distância

\begin{tabular}{c|c|c} 
Distância entre & Medida $(\mathrm{cm})$ & Avaliação \\
\hline Cama e roupeiro (Q1) & 104 & Atende \\
\hline Cama e roupeiro (Q2) & 74 & Não atende \\
\hline Cama e roupeiro (Q3) & 70 & Não atende \\
\hline Mesa e parede (Sala) & 48 & Não atende \\
\hline Tanque e prateleira superior (Lavanderia) & 85 & Não atende \\
\hline
\end{tabular}

Fonte: elaborado pelos autores, 2020.

Para esta a habitação a mesa da cozinha tem um de seus lados encostado na parede, porém seus outros lados têm livre circulação, conforme a Figura 3.

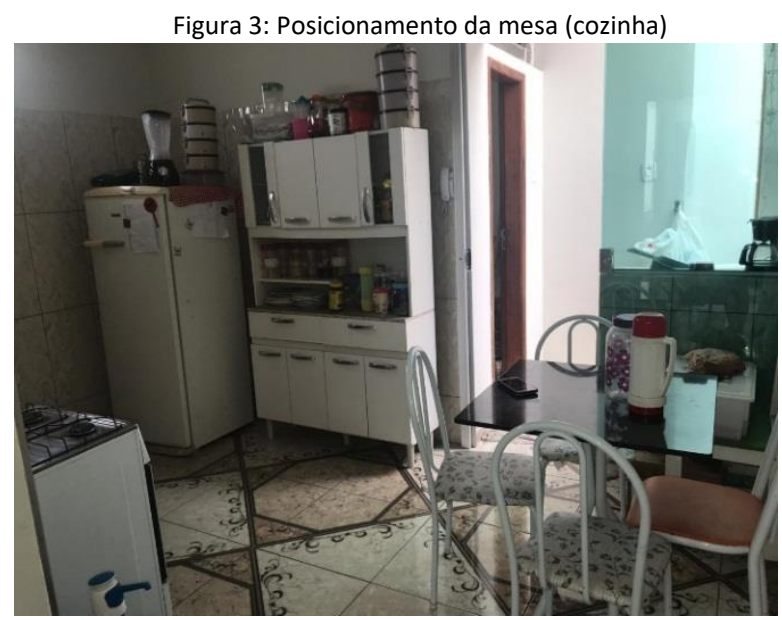

Fonte: elaborado pelos autores, 2020.

A Figura 4 apresenta a distância entre a cama e os roupeiros/cômoda nos quartos 1, 2 e 3, respectivamente. 


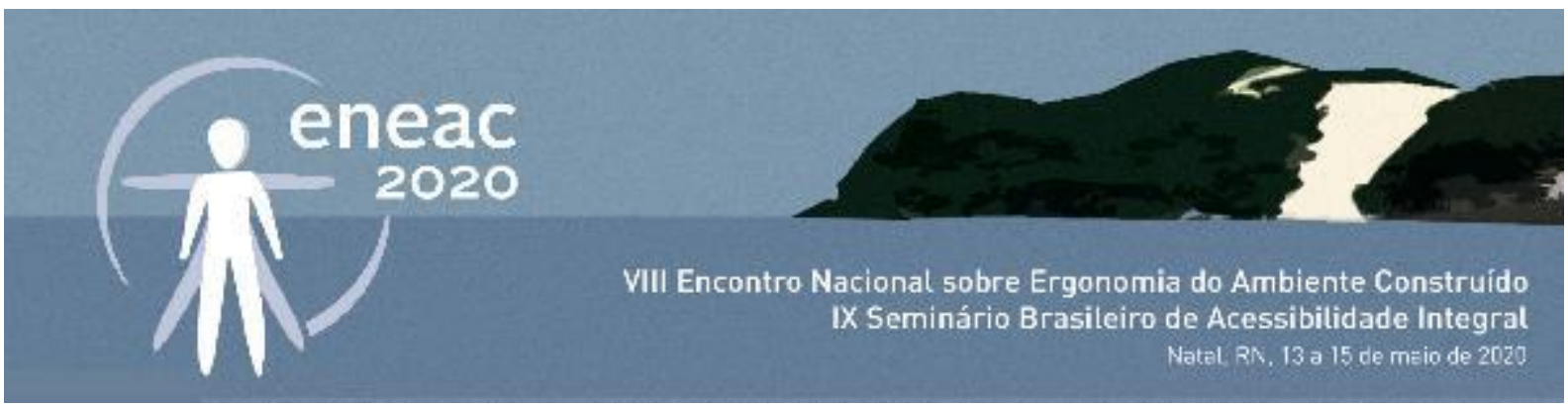

Figura 4: Distância entre a cama e os roupeiros nos quartos 1, 2 e 3
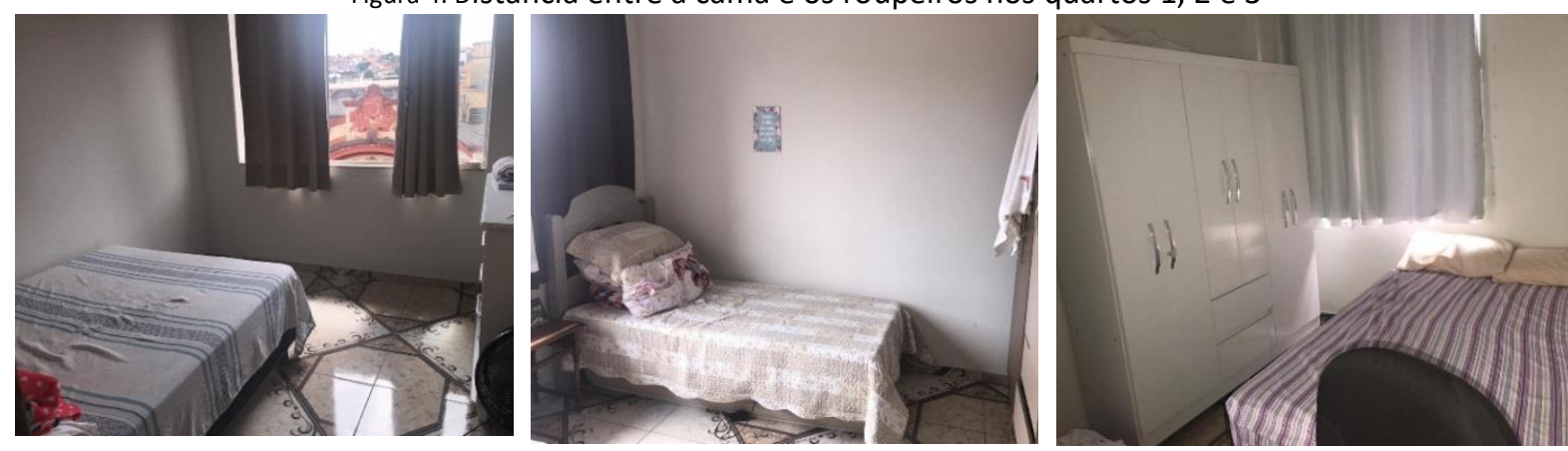

Fonte: elaborado pelos autores, 2020.

De forma geral, percebe-se que algumas das mobílias não atendem às medidas mínimas estabelecidas nas referências utilizadas para análise, o que pode prejudicar a realização das atividades diárias dos usuários, bem como afetar a qualidade de vida e saúde dos mesmos. Em $80 \%$ das medidas de distância entre mobílias analisadas os critérios não foram atendidos, além da distância de circulação e trabalho em frente ao tanque de lavar roupas que também não foi atendida.

\section{Espaço habitável e iluminação}

Na Tabela 9 estão apresentadas as medidas dos compartimentos da residência, bem como as avaliações quanto às condições de habitabilidade e iluminação de acordo com o Código de Obras do munícipio.

Tabela 9: Medidas e avaliações referentes à moradia

\begin{tabular}{|c|c|c|c|c|c|c|c|}
\hline Compartimento & $\begin{array}{l}\text { Área } \\
\left(\mathrm{m}^{2}\right)\end{array}$ & Avaliação & $\begin{array}{c}\text { Área das } \\
\text { aberturas } \\
\left(\mathrm{m}^{2}\right)\end{array}$ & $\begin{array}{c}\text { Área das } \\
\text { aberturas em } \\
\text { relação à área do } \\
\text { piso (\%) }\end{array}$ & Avaliação & Pé-direito (m) & Avaliação \\
\hline Sala de estar & 10,43 & Atende & 3,00 & 28,76 & Atende & 2,98 & Atende \\
\hline Q1 & 9,05 & Atende & 3,00 & 33,15 & Atende & 2,98 & Atende \\
\hline Q2 & 12,30 & Atende & 4,99 & 40,57 & Atende & 2,98 & Atende \\
\hline Q3 & 8,15 & Atende & 2,06 & 25,28 & Atende & 2,98 & Atende \\
\hline Q4 & 4,97 & Não atende & - & - & - & 2,98 & Atende \\
\hline Cozinha & 9,40 & Atende & 0,24 & 2,55 & Não atende & 2,98 & Atende \\
\hline Copa & 11,37 & Atende & 1,50 & 13,19 & Não atende & 2,98 & Atende \\
\hline B1 & 4,68 & Atende & 0,98 & 20,94 & Atende & 2,98 & Atende \\
\hline B2 & 1,28 & Não atende & - & - & - & 2,98 & Atende \\
\hline Lavanderia & 2,88 & Não atende & - & - & - & 2,98 & Atende \\
\hline
\end{tabular}

A partir da análise do espaço habitável percebe-se que três dos compartimentos possuem áreas inferiores ao mínimo estabelecido pelo Código de Obras (CO) do município, e que o pé-direito da residência atende ao mínimo estabelecido pelo $\mathrm{CO}$ da cidade. 


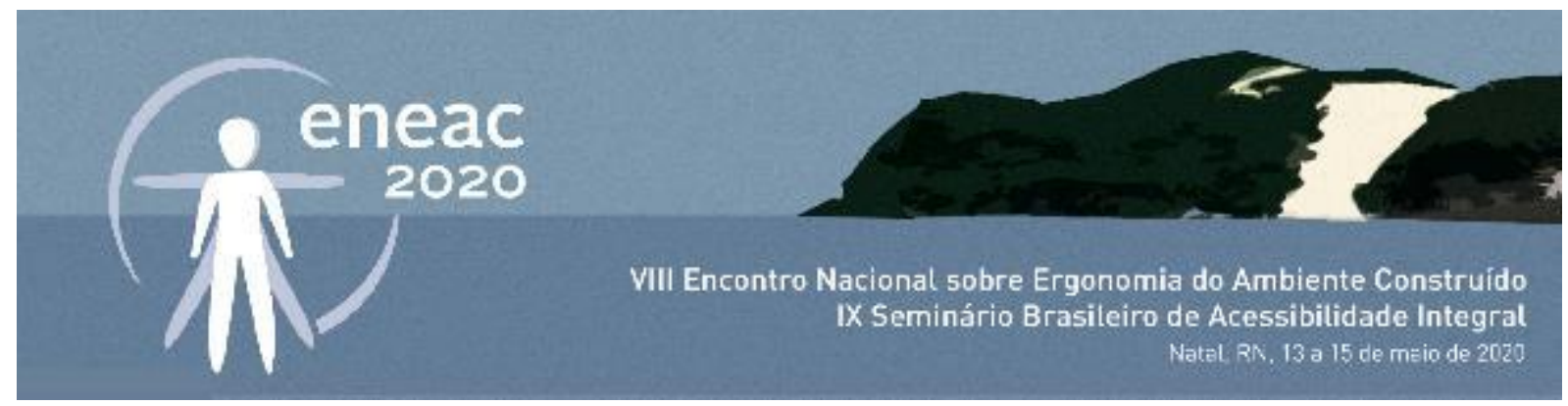

Destaca-se que o Q4 e o B2 não possuem janelas, o que afeta a luminosidade destes ambientes, prejudicando o conforto dos usuários neste sentido. Acredita-se que em termos de projeto, os dois compartimentos foram destinados ao uso da empregada.

As áreas dos vãos em relação à área do piso estão relacionadas ao conforto lumínico da residência. A cozinha e a copa não atendem ao mínimo estabelecido pela legislação quanto a este parâmetro, afetando a iluminação do ambiente, uma vez que as aberturas não são suficientes para promover uma boa luminosidade natural. Ademais, a lavanderia também não possui janelas, porém este cômodo contém uma claraboia que auxilia na iluminação do ambiente, conforme Figura 5.

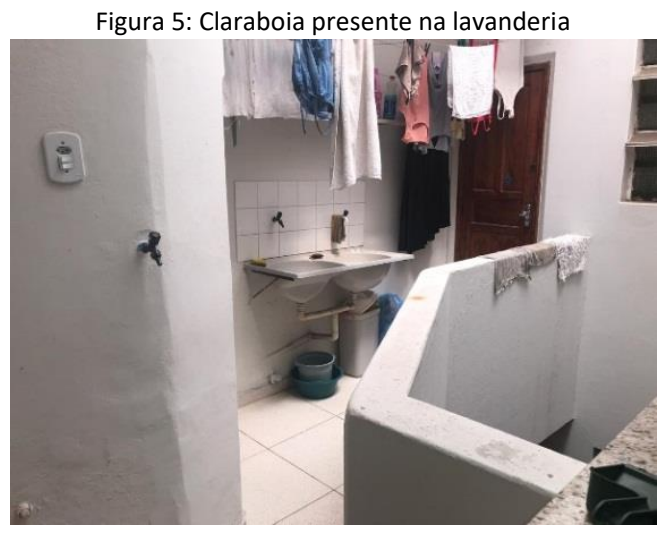

Fonte: elaborado pelos autores, 2020.

\section{Conforto térmico}

A Tabela 10 contém a avaliação dos compartimentos da residência quanto às condições de conforto térmico, de acordo com a orientação de cada um deles.

A orientação refere-se ao lado para o qual a abertura do cômodo está voltada.

Tabela 10: Orientação solar e avaliação

\begin{tabular}{c|c|c} 
Compartimento & Orientação & Avaliação \\
\hline Sala de estar & Sul & $\mathrm{R}$ \\
\hline $\mathrm{Q} 1$ & Leste & $\mathrm{O}$ \\
\hline $\mathrm{Q} 2$ & Leste & $\mathrm{O}$ \\
\hline $\mathrm{Q} 3$ & Oeste & $\mathrm{R}$ \\
\hline $\mathrm{Q} 4$ & Oeste & $\mathrm{R}$ \\
\hline Cozinha & Sul & $\mathrm{B}$ \\
\hline Copa & Sul & $\mathrm{R}$ \\
\hline B1 & Leste & $\mathrm{R}$ \\
\hline B2 & Oeste & $\mathrm{O}$ \\
\hline Lavanderia & Oeste & $\mathrm{O}$
\end{tabular}

Fonte: elaborado pelos autores, 2020. 


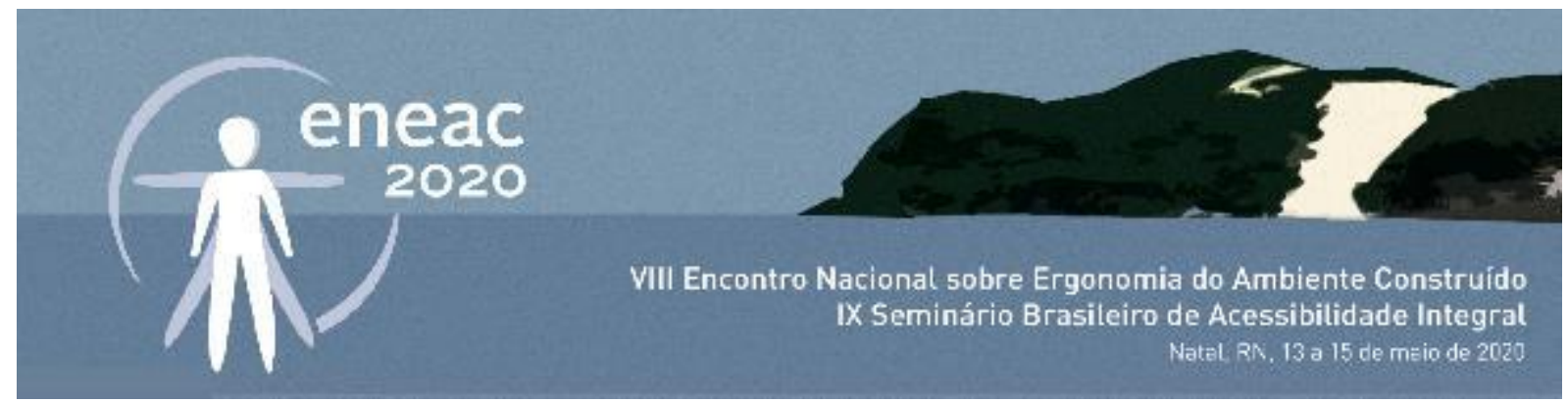

Como dito anteriormente, o Q4 e o B2 não possuem janelas, sendo assim, para a avaliação dos mesmos, considerou-se a direção para a qual a maior fachada destes compartimentos está voltada. $\mathrm{Na}$ cozinha, apesar de existir um vão voltado para uma direção considerada boa, destaca-se que este mesmo não é aberto, sendo feito de tijolos de vidro, logo não recebe ventilação, conforme Figura 6.

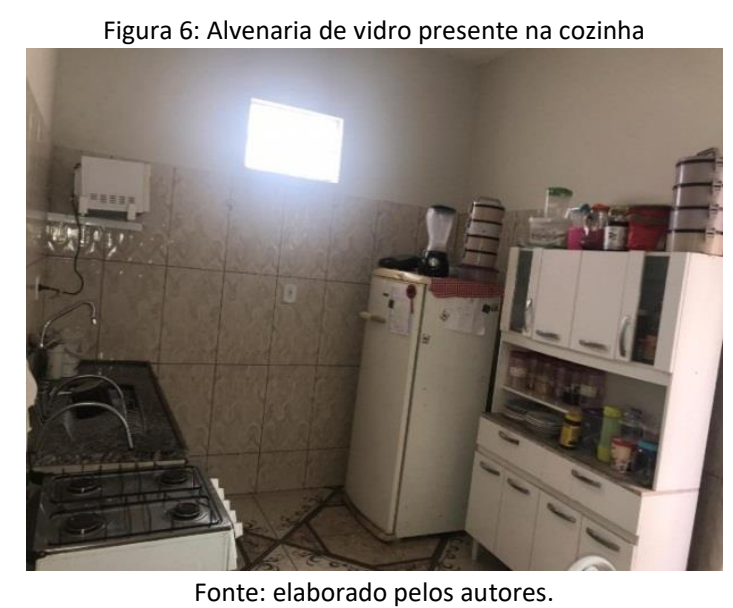

Analisando as avaliações contidas na Tabela 10, percebe-se que apenas quatro dos dez (40\%) cômodos da residência possuem uma orientação solar ótima, um (10\%) com orientação solar boa e os outros cinco cômodos (50\%) têm orientação solar considerada ruim. Com isso, percebe-se que o conforto térmico na residência é afetado pela incorreta implantação das aberturas relativas à orientação solar, o que prejudica o bem-estar dos moradores.

\section{CONSIDERAÇÕES FINAIS}

Em virtude dos resultados obtidos, conclui-se que a residência analisada não apresenta condições satisfatórias de conforto ambiental e ergonômicas. Destacando que, mais da metade das mobílias da moradia não atenderam às medidas mínimas estabelecidas. Além disso, em quase sua totalidade, as medidas de distância entre mobílias também não atenderam aos critérios de análise. Com isso, a movimentação dos usuários, sua adaptação e conforto ficam afetados, conduzindo a um mal-estar no ambiente.

Destaca-se o Q4 e o B2 como compartimentos de situação crítica, uma vez que possuem áreas inferiores ao mínimo estabelecido pelo $\mathrm{CO}$ do município e, ademais, não possuem janelas. Em vista disso, a habitabilidade, espacialidade, luminosidade e ventilação nestes ambientes ficam prejudicadas, gerando desconforto para os moradores. Além destes, a cozinha, local de intenso uso e realização de trabalho domiciliar, também possui condições de iluminação e ventilação precárias, fato observado no ato da visita à residência e corroborado pelos resultados na análise da área dos vãos em relação à área do piso.

Metade dos cômodos da habitação tem orientação solar ruim, o que interfere no conforto térmico da edificação, produzindo a necessidade de uso de meios de ventilação artificiais. 


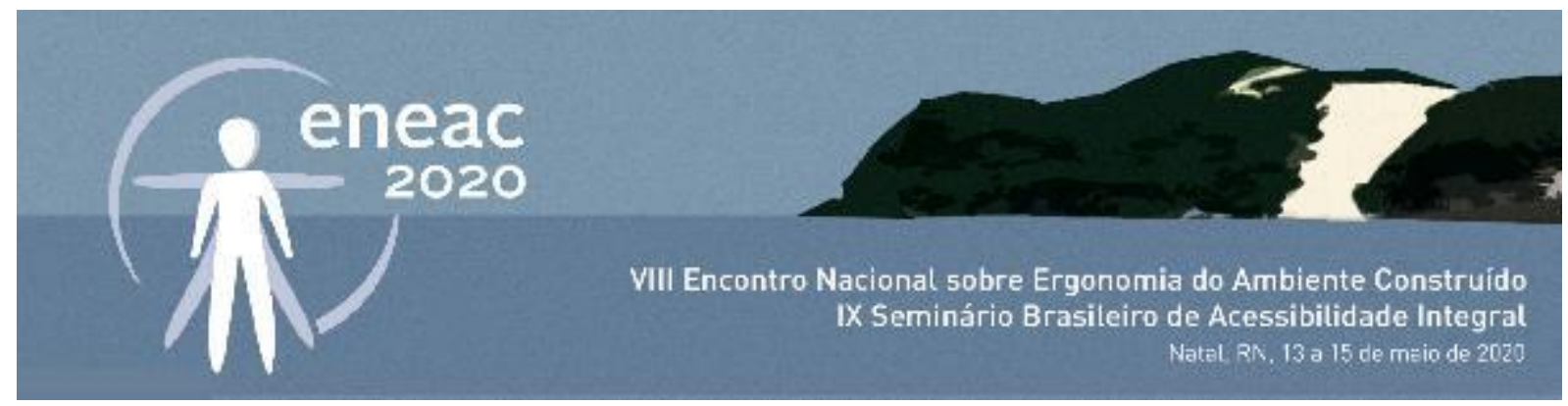

De uma perspectiva geral, a moradia analisada tem muitos fatores a serem readequados para que o conforto ambiental e a ergonomia sejam garantidos no ambiente.

\section{AGRADECIMENTOS}

Os autores agradecem ao NEIEMUC (Núcleo Estratégico e Interdisciplinar de Engenharia do Mucuri) e a UFVJM pelo apoio acadêmico.

\section{REFERÊNCIAS}

ANALYSIS SOL-AR. Laboratório de Eficiência Energética em Edificações. Disponível em: <http://www.labeee.ufsc.br/downloads/softwares/analysis-sol-ar > Acesso: nov, 2019.

CRESPILHO, F. E.; BORMIO, M. F.; STRABELI, G. I. Habitação Econômica, Acessibilidade e Conforto Ambiental: uma abordagem ergonômica da maneira como os projetos estão sendo pensados. In: Anais do VI Encontro Nacional de Ergonomia do Ambiente Construído. São Paulo: Blucher, 2016.

CÓDIGO DE OBRAS E EDIFICAÇÕES DO MUNICÍPIO DE TEÓFILO OTONI. Lei Complementar no 113 de 09 de agosto de 2016

IBGE. Instituto Brasileiro de Geografia e Estatística. Disponível em: <http://www.ibge.gov.br/cidadesat/topwindow.htm?1> Acesso: jan, 2020.

LABAKI, L. C.; BUENO-BARTHOLOMEI, C. L. (2001). Avaliação do Conforto Térmico e Luminoso de Prédios Escolares da Rede Pública. Campinas-SP. Encontro Nacional do Conforto no Ambiente Construído.

LAMBERTS, R; GHISI, E; PAPST, A. L; CARLO, J. C. (2005). Desempenho Térmico de Edificações. Universidade Federal de Santa Catarina.

LELIS, V.F.; FARIA, J.R.G; Paschoarell, L. Ergonomia do Ambiente Construído e APO na Perspectiva da Habitação Social: um quadro referencial e metodológico. $3^{\circ}$ Ergotrip Design: Design, Ergonomia e Interação Humano-Computador. UFRN, Natal, RN, 2013.

LELIS, V.F. Análise de Habitações Sociais na Perspectiva da Ergonomia do Ambiente Construído: estudos de caso do POROMORE. Dissertação de Mestrado. Programa de Pós Graduação em Design, da Faculdade de, Arquitetura, Artes e Comunicação da Universidade Estadual Paulista Júlio de Mesquita Filho. Bauru, São Paulo, 2015.

LOPES, Maria Valéria Affonso. Ergonomia aplicada à habitação: o caso do usuário enfermo. Dissertação (Mestrado - Área de Concentração: Tecnologia da Arquitetura) - FAUUSP, 2006.

MONT' ALVÃO, C. A ergonomia do Ambiente Construído no Brasil. In: MONT`ALVÃO, C.; VILLAROUCO, V.(org) Um novo olhar para o projeto: a ergonomia no ambiente construído. Rio de Janeiro: 2AB, 2011.

PAIVA, M.M.B.; SANTOS, V. M. Ergonomia no Ambiente Construído em Moradia Coletiva para Idosos: estudo de caso em Portugal. Revista Ação Ergonômica, v.7, n. 3, 2012.

PEDRO, J. B.; VASCONCELOS, L.; MONTEIRO, M.; JERÓNIMO, C. Dimensões do Mobiliário e do Equipamento na Habitação. Lisboa: LNEC, 2006.

PRONK, E. Dimensionamento em Arquitetura. UFPB, Editora Universitária, 2003.

SOUZA, J.E. O Interior da Habitação Popular: Uma Análise do Arranjo do Mobiliário pela Ótica da Ergonomia. Revista Online Especialize IPOG, 2013.

VASCONCELOS, C.Q. Análise da Funcionalidade e de Ergonomia em Habitações Compactas. Universidade Federal de Santa Catarina (UFSC). Programa de Pós-Graduação em Arquitetura e Urbanismo. Dissertação de Mestrado, Florianópolis, 2011.

VILLAROUCO, V. Avaliação ergonômica do projeto arquitetônico. In: Congresso Latino-Americano de Ergonomia, 7.; Seminário Brasileiro de Acessibilidade Integral, 1.; Congresso Brasileiro de Ergonomia, 12. 2002a, Recife. Anais. ABERGO, 2002. 